\title{
Cardiovascular Responses to Alpha-Melanocyte Stimulating Hormone during the Perinatal Period in Sheep
}

\author{
ANIBAL J. LLANOS, ${ }^{(23)}$ MARIA SERON-FERRE, JANAKIRAMAN RAMACHANDRAN, \\ ROBERT K. CREASY, MICHAEL A. HEYMANN, ${ }^{(26)}$ AND ABRAHAM M. RUDOLPH \\ Departments of Obstetrics, Gynecology and Reproductive Sciences, and Pediatrics, Reproductive Endocrinology \\ Center, Cardiovascular Research Institute, and Hormone Research Laboratory, University of California, San \\ Francisco, California, USA
}

\section{Summary}

To determine the effects of alpha-melanocyte stimulating hormone $(\alpha \mathrm{MSH})$ on the circulation of undisturbed fetal sheep and young lambs and to explore possible mechanisms of actions, we examined the responses of ascending aortic blood flow, heart rate, stroke volume, and arterial blood pressure to a single intravenous injection of $\alpha \mathrm{MSH}, \mathrm{ACTH}$, cortisol and to $\alpha \mathrm{MSH}$ after beta-adrenergic blockade. We also measured cardiac output and organ blood flows before and after $\alpha$ MSH injection by the radionuclide labeled microsphere technique. $\alpha \mathrm{MSH}$ increased ascending aortic blood flow from $249 \pm 23$ to $327 \pm 30 \mathrm{ml}$. $\mathrm{min}^{-1} \cdot \mathrm{kg}^{-1}(P<0.001)$, heart rate from $111 \pm 10$ to $126 \pm 11$ $\min ^{-1},(P<0.001)$ and stroke volume from $2.32 \pm 0.21$ to 2.75 $\pm 0.20 \mathrm{ml} \cdot \mathrm{kg}^{-1},(P<0.001)$ in 10 young lambs $15-30$-day-old. $\alpha$ MSH decreased mean systemic arterial blood pressure from $42.6 \pm 1.7$ to $39.3 \pm 1.6 \mathrm{mmHg}(P<0.001)$ in fetal sheep and $\min ^{-1},(P<0.001)$ and stroke volume from $2.32 \pm 0.21$ to 2.75 $\pm 0.20 \mathrm{ml} \cdot \mathrm{kg}^{-1},(P<0.001)$ in 10 young lambs $15-30$-days-old. $\alpha \mathrm{MSH}$ decreased mean systemic arterial blood pressure from $42.6 \pm 1.7$ to $39.3 \pm 1.6 \mathrm{mmHg}(P<0.001)$ in fetal sheep and from $77.5 \pm 4.5$ to $72.7 \pm 4.3 \mathrm{mmHg}(P<0.001)$ in young lambs. In six additional young lambs (20-35-day-old) cardiac output, measured by microspheres, increased with $\alpha$ MSH from $216 \pm$ 20 to $261 \pm 19 \mathrm{ml} \cdot \mathrm{min}^{-1} \cdot \mathrm{kg}^{-1}(P<0.001)$. $\alpha$ MSH also increased blood flow to the myocardium from $104 \pm 22$ to $151 \pm 26 \mathrm{ml}$. $\min ^{-1} \cdot 100 \mathrm{~g}^{-1}(P<0.001)$, to the adrenals from $195 \pm 38$ to 243 $\pm 41 \mathrm{ml} \cdot \mathrm{min}^{-1} \cdot 100 \mathrm{~g}^{-1},(P<0.05)$, and to the lungs from 157 \pm 31 to $468 \pm 81 \mathrm{ml} \cdot \mathrm{min}^{-1} \cdot 100 \mathrm{~g}^{-1}(P<0.005)$. The increase in lung flow suggests an increase in peripheral arteriovenous shunting in young lambs. There was no change in blood flow to the brain, thyroid, spleen, kidneys, gut, thymus, liver, and carcass. ACTH or cortisol did not have cardiovascular effects in fetal or young lambs. Beta-adrenergic blockade with propranolol did not prevent the increase in aortic blood flow (from $296 \pm 53$ to $426 \pm 75 \mathrm{ml} \cdot \mathrm{min}^{-1} \cdot \mathrm{kg}^{-1}, P<0.001$ ) and heart rate (from 81 \pm 4 to $106 \pm 3 \mathrm{~min}^{-1}, P<0.001$ ) observed in four young lambs, 15-21 days of age, after the injection of $\alpha \mathrm{MSH}$, but prevented the fall in arterial blood pressure. These responses indicate that $\alpha$ MSH does not act through beta-adrenergic receptors of the heart of young lambs. The observation that the cardiovascular system of fetal and young lambs responds to $\alpha$ MSH suggests that $\alpha \mathrm{MSH}$ or related substances could play a role in regulating the circulation in the perinatal period.

\section{Abbreviation}

$\alpha \mathrm{MSH}$, alpha-melanocyte stimulating hormone

We (14) and others (6) have shown that the administration of $\alpha \mathrm{MSH}$, a 13-aminoacid peptide derived from ACTH, stimulates adrenal function in fetal and newborn lambs. While performing those studies we observed cardiovascular effects after the injection of $\alpha \mathrm{MSH}$. $\alpha \mathrm{MSH}$ produces an increase in heart rate in both humans (8) and in the heart-lung preparation in adult dogs (10), and also decreases arterial blood pressure in adult rabbits (3). Because no information was available about the cardiovascular effects of $\alpha \mathrm{MSH}$ in the perinatal period, we measured the effects of $\alpha \mathrm{MSH}$ on heart rate, arterial blood pressure, stroke volume, and ascending aortic blood flow in young lambs and fetal sheep, and on cardiac output and its distribution in young lambs. ACTH was administered to compare the effects of the precursor with those of $\alpha \mathrm{MSH}$. Because $\alpha \mathrm{MSH}$ increases plasma concentrations of cortisol in fetal and newborn sheep (14), we administered cortisol to investigate whether this hormone was involved in the cardiovascular effects of $\alpha \mathrm{MSH}$. To assess whether the cardiovascular effects of $\alpha \mathrm{MSH}$ were mediated through beta-adrenergic receptors we studied the cardiovascular response to $\alpha \mathrm{MSH}$ after beta-adrenergic blockade with propranolol.

\section{MATERIALS AND METHODS}

Animals. Experiments were performed in 16 young lambs (6$16 \mathrm{~kg}$ body weight) $15-35$ days after birth, and in six fetal sheep $(1.95-2.9 \mathrm{~kg})$ with gestational ages of $110-133$ days.

Surgical procedures. Young lambs were surgically prepared as described previously (9). Briefly, each lamb was anesthetized with fluothane, the trachea was intubated with a cuffed endotracheal tube, and ventilation was maintained with a Harvard respiratory pump. The left thorax was opened through the third intercostal space. Polyvinyl catheters were inserted into the internal thoracic artery and vein, and advanced to the brachiocephalic trunk and superior vena cava, respectively. The pericardium was incised and a catheter was inserted through a pursestring suture into the left atrium. In 10 of the 16 young lambs a precalibrated electromagnetic flow transducer ( $\mathrm{C}$ and $\mathrm{C}$ Instruments) was placed around the ascending aorta just above the coronary arteries to measure left ventricular output, excluding coronary blood flow. All catheters and the flow transducer cable were led to the skin on the left chest, where they were protected by a Teflon cloth pouch sewn to the skin. A femoral vein and artery were also catheterized. All catheters were filled with heparin and plugged. Penicillin $\mathrm{G}(100,000 \mathrm{IU} / \mathrm{kg})$ and kanamycin $(15 \mathrm{mg} / \mathrm{kg})$ were injected intramuscularly every day for 5 days after surgery. Once the lambs recovered from anesthesia, they were returned to their mothers where they remained except during the time of the studies.

Fetal sheep were surgically prepared as described previously (18). Lower body analgesia was achieved in the ewes by low spinal injection of $2 \mathrm{ml}(40 \mathrm{mg})$ of tetracaine hydrochloride $(2 \%$ Pontocaine). All fetal surgical procedures were performed under 
local anesthesia ( $0.5 \%$ lidocaine hydrochloride). Polyvinyl catheters were inserted into a fetal jugular and femoral vein, a carotid and femoral artery, and also into the amniotic cavity. The left thorax was opened through the third intercostal space and the pericardium was incised. A precalibrated electromagnetic flow transducer was applied around the fetal ascending aorta distal to the origin of the coronary arteries to measure left ventricular output, minus coronary blood flow. A chest drainage tube was placed in the left pleural cavity and the chest closed. The uterine incision was closed and all catheters and the flow transducer cable were led to the ewe's skin on the left flank, where they were protected by a Teflon cloth pouch sewn to the skin. Penicillin $G$ $(100,000 \mathrm{IU})$ and kanamycin $(500 \mathrm{mg})$ were injected into the amniotic cavity on the day of surgery and for 5 days thereafter.

Experiments were started 4 days after surgery. We brought the pregnant ewes and lambs into the study room at least $60 \mathrm{~min}$ before the experiments were started. The ewes stood quietly in a study cage. The lambs were suspended in a canvas sling, blindfolded, and the experiments were done when the animals were quiet and relaxed, or sleeping.

$\alpha M S H$, and $A C T H$ experiments. Seventy-five micrograms of $\alpha \mathrm{MSH}$, isolated from porcine pituitaries in the Hormone Research Laboratory (University of California, San Francisco) or synthetic $\alpha \mathrm{MSH}$, which was purchased from Beckman Instruments (Palo Alto, CA), was dissolved in $2 \mathrm{ml}$ of $0.2 \%$ bovine serum albumin, and injected over $1 \mathrm{~min}$ into the femoral venous catheter of six fetal (110-133 days of gestation) and 10 young lambs (15-30 days of age). The catheter was flushed with a $2 \mathrm{ml}$ of $0.9 \%$ sodium chloride solution.

In a separate experiment, two of the six sheep fetuses were treated successively with $5,15,75,500$, and $1000 \mu \mathrm{g}$ of $\alpha \mathrm{MSH}$ dissolved in $2 \mathrm{ml}$ of $0.2 \%$ bovine serum. Each dose of $\alpha \mathrm{MSH}$ was injected after the cardiovascular response from the previous injection had returned to basal values.

Fifty micrograms of ACTH (Cortrosyn) dissolved in $0.9 \%$ sodium chloride were injected over $1 \mathrm{~min}$ into a femoral venous catheter in a total volume of $1 \mathrm{ml}$. The catheter was flushed with $2 \mathrm{ml}$ of $0.9 \%$ sodium chloride solution. This dose was administered to all six fetuses but to only six of 16 young lambs.

We injected $2 \mathrm{ml}$ of $0.9 \%$ sodium chloride solution and $2 \mathrm{ml}$ of $0.2 \%$ bovine serum albumin in sodium chloride solution as controls. Each solution was injected into six fetal sheep and into six young lambs in the same manner as described above. The hormones or $0.9 \%$ sodium chloride were given in random order.

Aortic blood flow, systolic, diastolic, and mean arterial pressures and heart rate were recorded continuously for at least 40 min before and at least $120 \mathrm{~min}$ after the injections of the hormones. In six of the young lambs (20-35 days of age), we measured cardiac output and organ blood flows before and 10 min after the injection of $75 \mu \mathrm{g}$ of $\alpha \mathrm{MSH}$.

Propranolol and $\alpha M S H$ experiments. To assess whether the cardiovascular responses to $\alpha \mathrm{MSH}$ were mediated through symptheticoadrenal mechanisms, we administered propranolol to block the beta-adrenergic receptors. Propranolol was given intravenously as a bolus injection of $1 \mathrm{mg} / \mathrm{kg}$ followed by an infusion of $50 \mu \mathrm{g} / \mathrm{kg}$ per min for $30 \mathrm{~min}$ to four young lambs (15-21 days of age). The completeness of the blockade was confirmed by the lack of response of the cardiovascular variables to an injection of isoproterenol $0.1 \mu \mathrm{g} / \mathrm{kg}$ up to a total dose of 2 $\mu \mathrm{g}$. After complete blockade was demonstrated, $75 \mu \mathrm{g}$ of $\alpha \mathrm{MSH}$ was given intravenously. The persistence of the blockade was checked $15 \mathrm{~min}$ after $\alpha \mathrm{MSH}$ injection again by injection of isoproterenol.

Cortisol experiments. To assess whether the cardiovascular responses to $\alpha \mathrm{MSH}$ were mediated through the release of cortisol, approximately 8 times the estimated daily cortisol production of a newborn lamb (17) was injected. Cortisol (Solucortef) $2.5 \mathrm{mg}$ / $\mathrm{kg}$ was administered intravenously as a bolus injection in five fetal sheep and in six young lambs.

Methods of measurements. Arterial blood $\mathrm{PO}_{2}, \mathrm{PCO}_{2}, \mathrm{pH}$, and hematocrit were measured daily, as well as just before and 20 min after the injection of $\alpha \mathrm{MSH}$ or ACTH. Systemic arterial blood pressure was measured continuously with a Statham $\mathrm{P} 23 \mathrm{Db}$ pressure transducer. Ascending aortic blood flow was recorded continuously with a Statham SP 2202 flowmeter. Heart rate was measured by a cardiotachometer with the electromagnetic flow signal or the arterial pressure as a trigger. In the fetal studies, maternal arterial and intraamniotic pressure also were measured. The electromagnetic flow transducer and flowmeter system had a frequency response of $100 \mathrm{~Hz}$, a reproducibility of $\pm 2 \%$, and a $5 \%$ error. The pressures, heart rate, and flow were recorded on a Beckman Dynograph multiple channel direct writing recorder. Stroke volume was calculated by dividing ascending aortic blood flow $\left(\mathrm{ml} \cdot \mathrm{kg}^{-1} \cdot \mathrm{min}^{-1}\right)$ by heart rate $\left(\mathrm{min}^{-1}\right)$. Fetal arterial pressure was calculated by subtracting the amniotic fluid pressure from the measured fetal arterial pressure.

In the young lambs, cardiac output and its distribution were measured by the radionuclide labeled microsphere technique (7). We injected microspheres, $15 \mu \mathrm{m}$ in diameter, into the left atrium. Reference samples were taken simultaneously from the internal thoracic and femoral arteries. Before the second measurement of cardiac output, adult sheep blood equivalent to the amount withdrawn for the reference samples was infused. The lambs were sacrificed and the individual organs were dissected, incinerated in an oven, and counted for radioactivity in a 512 channel multichannel pulse-weight analyzer (Searle Analytic, Des Plaines, IL), as described before (7). Blood flow to the various organs was calculated from the counts in the individual organs, the counts in the reference samples, and the withdrawal rate of the reference samples by using a 370 IBM computer (7). As a check of adequate mixing of microspheres in arterial blood, the right and left kidneys and hemisections of the brain were counted separately. The number of microspheres in each organ was always more than 400 .

Statistics and Calculations. We calculated the basal cardiovascular values before the injection of hormones or drugs by averaging the measurements at 1 -min intervals for 10 -min periods. We repeated this procedure four times, covering $40 \mathrm{~min}$ before the injections. After the injection we averaged the measurements at 1 -min intervals for 10 -min periods. We repeated this procedure five times for a 50 -min period after the injection.

In studies of the effect of propranolol on a $\alpha \mathrm{MSH}$ response, the control values were calculated by averaging the measurements at 1 -min intervals for $40 \mathrm{~min}$ before the propranolol injection. The values were assessed by the same method for 15 min after propranolol injection, and also for $15 \mathrm{~min}$ after $\alpha \mathrm{MSH}$ was given during the propranolol blockade.

The cardiovascular responses to hormones and drugs were analyzed by a single factor analysis of variance for repeated measurements and the Newman-Keuls test (22). The response of cardiac output and organ blood flows were analyzed by Student's paired $t$ test. $P<0.05$ was considered statistically significant. The values given in the text are means \pm S.E.

\section{RESULTS}

Arterial blood gases, $\mathrm{pH}$, and hematocrit. Resting arterial blood gases, $\mathrm{pH}$, and hematocrits observed in fetuses $\left(\mathrm{PO}_{2}, 21 \pm 1\right.$ torr; $\mathrm{PCO}_{2}, 46 \pm 2$ torr; $\mathrm{pH}, 7.38 \pm 0.05$ and $\mathrm{Ht}, 31 \pm 2 \%$ ) and lambs $\left(\mathrm{PO}_{2} 82 \pm 4\right.$, torr; $\mathrm{PCO}_{2}, 39 \pm 1$ torr; $\mathrm{pH}, 7.43 \pm 0.02$, and $\mathrm{Ht}$, $29 \pm 3 \%$ ) were similar to values in normal sheep of similar age $(9,15)$. The blood gases, $\mathrm{pH}$, and hematocrit did not change after the injection of $\alpha \mathrm{MSH}$, ACTH, cortisol, or propranolol.

Cardiovascular responses. Injection of $0.9 \%$ sodium chloride or $0.2 \%$ bovine serum albumin had no effect on ascending aortic blood flow, heart rate, stroke volume, or blood pressure in either young or fetal sheep. In young lambs, $\alpha \mathrm{MSH}$ increased cardiac output as measured either by electromagnetic flow transducer (from $249 \pm 23$ to $327 \pm 30 \mathrm{ml} \cdot \mathrm{min}^{-1} \cdot \mathrm{kg}^{-1}, P<0.001$, Fig. 1) or by radionuclide labeled microspheres (from $216 \pm 20$ to 261 $\pm 19 \mathrm{ml} \cdot \mathrm{min}^{-1} \cdot \mathrm{kg}^{-1}, P<0.001$, Table 1): heart rate rose (from $111 \pm 10$ to $126 \pm 11 \mathrm{~min}^{-1}, P<0.001$, Fig. 1) and stroke 


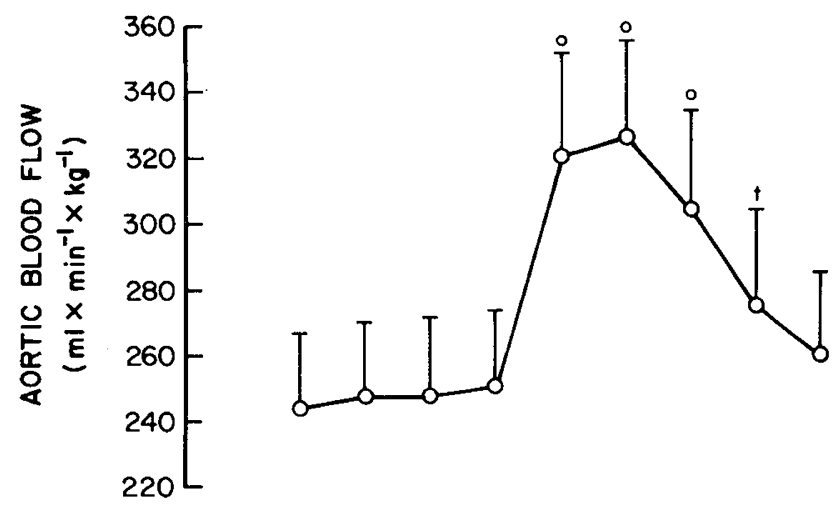

volume rose (from $2.32 \pm 0.21$ to $2.75 \pm 0.20 \mathrm{ml} \cdot \mathrm{kg}^{-1}, P<$ 0.001 , Fig. 3). $\alpha \mathrm{MSH}$ decreased the mean systemic arterial pressure from $77.5 \pm 4.5$ to $72.7 \pm 4.3 \mathrm{mmHg}, P<0.001$, Figure 1.

In fetal sheep, ascending aortic blood flow and heart rate increased (from $141 \pm 32$ to $170 \pm 33 \mathrm{ml} \cdot \mathrm{min}^{-1} \cdot \mathrm{kg}^{-1}, P<0.01$, Fig. 2; and from $179 \pm 10$ to $208 \pm 7 \mathrm{~min}^{-1}, P<0.05$, Fig. 2, respectively), and mean systemic arterial pressure decreased from $42.6 \pm 1.7$ to $39.3 \pm 1.6 \mathrm{mmHg}, P<0.001$, after $\alpha \mathrm{MSH}$ injection (Fig. 2). The stroke volume did not change (from $0.78 \pm 0.16$ to $0.88 \pm 0.17 \mathrm{ml} \cdot \mathrm{kg}^{-1}, P>0.20$, Fig. 3). Aortic blood flow increased only $20 \%$ in the fetal sheep as compared with a $31 \%$ increase in young lambs after the same dose of $\alpha \mathrm{MSH}$. An average increase in cardiac output of $2.5,4$, and $15 \%$ was observed in the two fetal sheep injected with 5,10 , and $15 \mu \mathrm{g}$, respectively. No further increases in aortic blood flow were

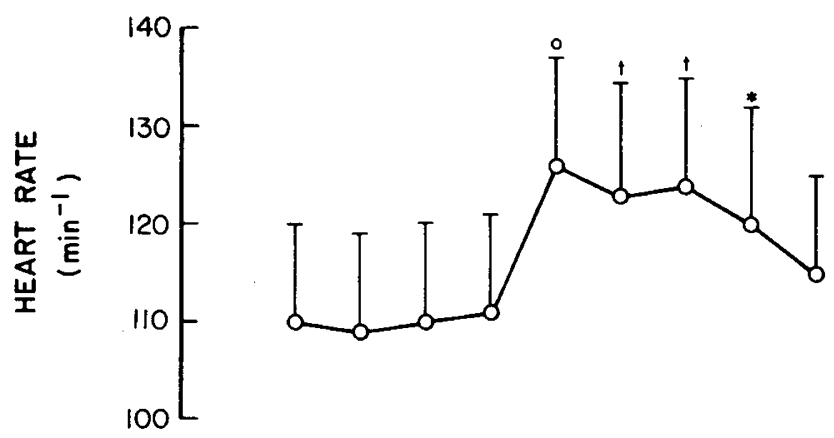

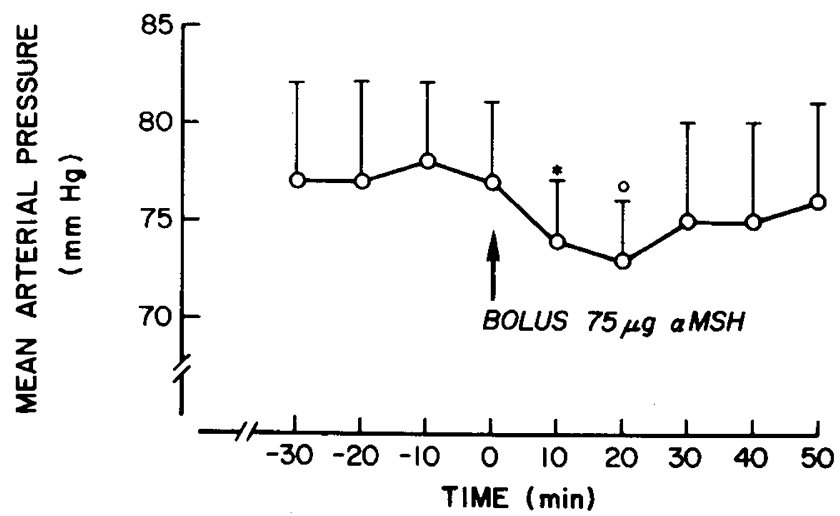

Fig. 1. Cardiovascular responses mean \pm S.E. of 10 young lambs $(15-$ 30 -days old) to an intravenous injection of $75 \mu \mathrm{g} \alpha \mathrm{MSH}$ (see text). ${ }^{\circ} P<$ $0.001,{ }^{+} P<0.005$ and ${ }^{*} P<0.05$ when compared with the mean of the basal values.

Table 1. Cardiac output and organ blood flows before and 10 min after the injection of $75 \mu \mathrm{g}$ of $\alpha M S H^{1}$

\begin{tabular}{lcc}
\hline & Basal & $\alpha \mathrm{MSH}$ \\
\hline $\begin{array}{l}\text { Cardiac output } \\
\left(\mathrm{ml} \cdot \mathrm{min}^{-1} \cdot \mathrm{kg}^{-1}\right)\end{array}$ & $216 \pm 20$ & $261 \pm 19^{\circ}$ \\
$\begin{array}{l}\text { Organ blood flows } \\
\left(\mathrm{ml} \cdot \mathrm{min}^{-1} \cdot 100 \mathrm{~g}^{-1}\right)\end{array}$ & & \\
Heart & $104 \pm 22$ & $151 \pm 26^{\circ}$ \\
Adrenals & $195 \pm 38$ & $243 \pm 41^{*}$ \\
Lungs & $157 \pm 31$ & $468 \pm 81 \dagger$ \\
Brain & $78 \pm 6$ & $86 \pm 5$ \\
Thyroid & $52 \pm 10$ & $59 \pm 11$ \\
Spleen & $186 \pm 22$ & $136 \pm 56$ \\
Kidneys & $311 \pm 34$ & $289 \pm 27$ \\
Gut & $75 \pm 6$ & $71 \pm 6$ \\
Thymus & $32 \pm 4$ & $29 \pm 3$ \\
Liver & $20 \pm 2$ & $19 \pm 4$ \\
Carcass & $11 \pm 1$ & $11 \pm 2$ \\
\hline
\end{tabular}

${ }^{1}$ All values are expressed as mean \pm S.E. of six young lambs (20-35day-old). ${ }^{\circ} P<0.001 ; \dagger P<0.005$; and ${ }^{*} P<0.05$. observed with 500 and $1000 \mu \mathrm{g} \alpha \mathrm{MSH}(14 \%$ and $17 \%$, respectively). The increase in heart rate (15\%) and the decrease in mean arterial pressure (7\%) were percentagewise similar when fetuses are compared to young lambs.
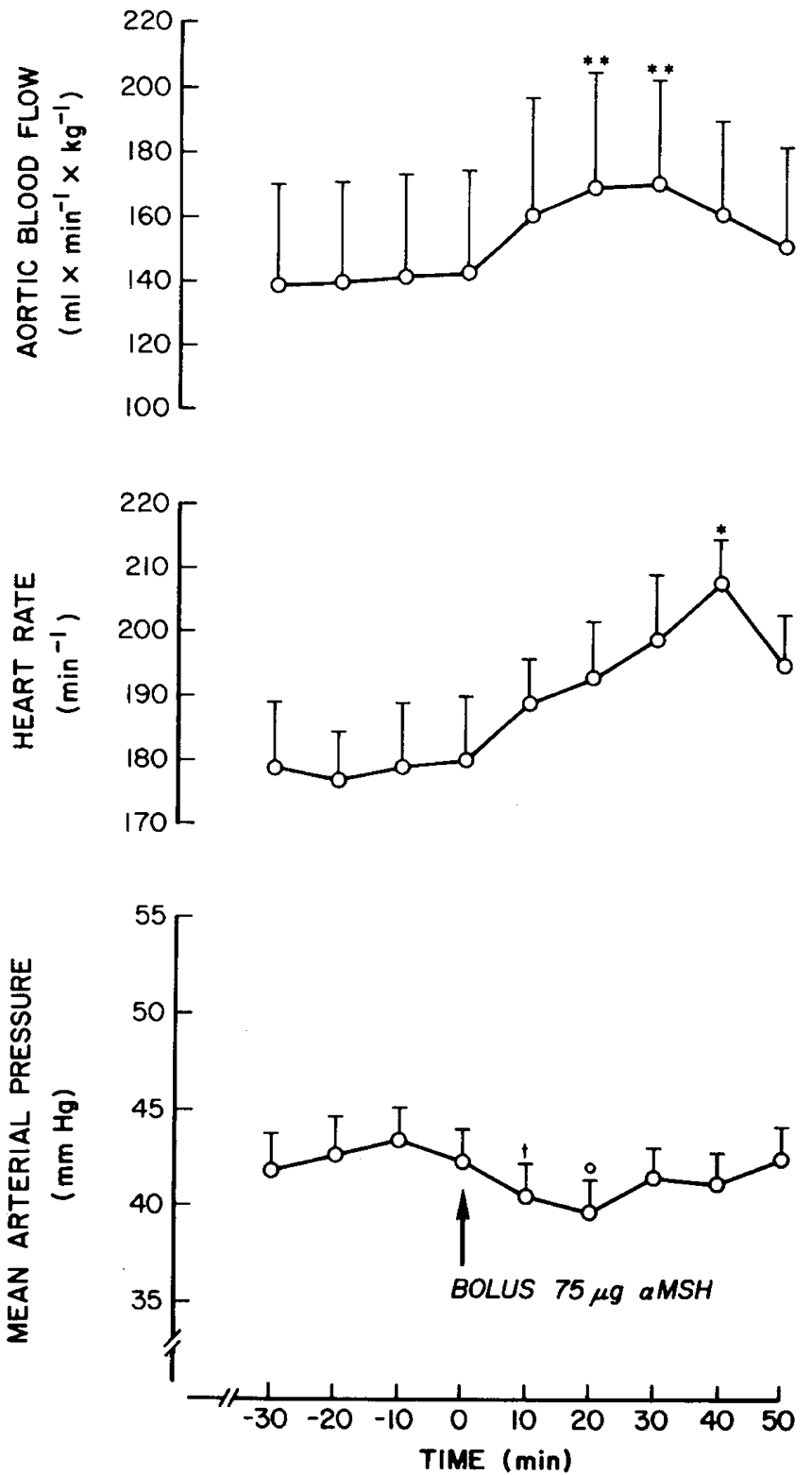

Fig. 2. Cardiovascular responses (mean \pm S.E.) of six fetal sheep (110-133 days of gestation) to an intravenous injection of $75 \mu \mathrm{g} \alpha \mathrm{MSH}$ (see text). ${ }^{\circ} P<0.001,{ }^{+} P<0.005,{ }^{* *} P<0.01$, and ${ }^{*} P<0.05$ when compared with the mean of the basal values. 

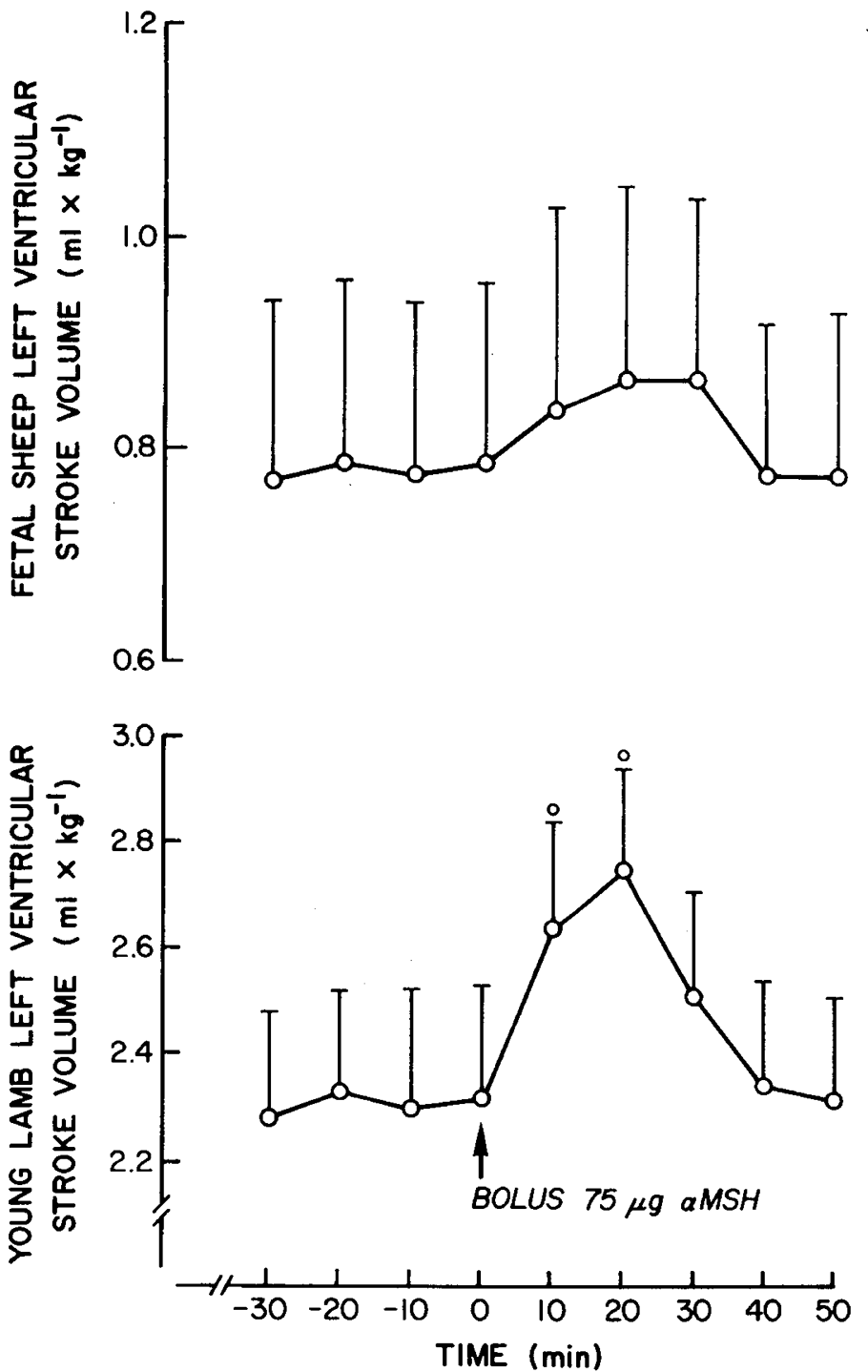

Fig. 3. Left ventricular stroke volume response (mean \pm S.E.) of six fetal sheep (110-133 days of gestation and 10 young lambs (15-30-daysold) to an intravenous injection of $75 \mu \mathrm{g} \alpha \mathrm{MSH}$ (see text). ${ }^{\circ} \mathrm{P}<0.001$ when compared with the mean of the basal values.

The cardiovascular variables did not change significantly after the injection of $50 \mu \mathrm{g}$ of ACTH in the young lambs or fetal sheep (data not shown), but the pattern of responses was similar to that observed after the injection of $\alpha \mathrm{MSH}$.

Cortisol did not alter heart rate, blood pressure, aortic flow, or stroke volume in young lambs or fetal sheep.

Effects of $\beta$-adrenergic blockade on $\alpha M S H$ response. Aortic blood flow and heart rate decreased after the injection of propranolol, but the rise in aortic blood flow (from $296 \pm 53$ to 426 $\pm 75 \mathrm{ml} \cdot \mathrm{min}^{-1} \cdot \mathrm{kg}^{-1} ; P<0.001$ ) and heart rate (from $81 \pm 4$ to $106 \pm 3 \mathrm{~min}^{-1} ; P<0.001$ ) after the injection of $\alpha \mathrm{MSH}$ (Fig. 4) was not prevented. In contrast, the decrease in mean arterial blood pressure induced by $\alpha \mathrm{MSH}$ was not observed when $\alpha \mathrm{MSH}$ was administered after propranolol blockade $(80 \pm 5$ before versus $79 \pm 6 \mathrm{mmHg}$ after $\alpha \mathrm{MSH}$ injection.)

Organ blood flows before and after $\alpha M S H$ injection. Blood flow to the heart, adrenals, and lungs increased after the injection of $\alpha \mathrm{MSH}$. No significant changes in blood flows to the brain, thyroid, spleen, kidneys, gut, thymus, liver, and carcass were observed after $\alpha \mathrm{MSH}$ injection (Table 1).

\section{DISCUSSION}

Our data demonstrate that $\alpha \mathrm{MSH}$ increases ascending aorta blood flow and heart rate and decreases mean systemic arterial blood pressure in both fetal sheep and young lambs. Also, $\alpha \mathrm{MSH}$ increases stroke volume and blood flow to the heart, adrenals, and lungs in young lambs. The mechanisms by which $\alpha \mathrm{MSH}$ exerts these actions are not known. The increase in aortic blood flow produced by $\alpha \mathrm{MSH}$ could be due to an increase in heart rate because it has been shown that cardiac output in sheep fetuses is influenced by changes in heart rate (18) or to a decrease in mean arterial blood pressure by decreasing the afterload. Our data suggest, too, an increase in cardiac contractility in young lambs because we observed an increase in stroke volume and also a rise of aortic blood flow in the absence of a fall of mean arterial pressure after propranolol. In agreement with this suggestion, Aldinger et al. (1) observed that $\alpha \mathrm{MSH}$ increases the venticular contractile force of anesthetized dogs. It has also been shown that cardiac contractility increases after the administration of other polypeptide hormones, parathormone (2), and glucagon (16). The decreased mean arterial blood pressure in the presence of an increase in aortic blood flow suggests that $\alpha \mathrm{MSH}$ induces a decrease in peripheral resistance in both young lambs and fetal sheep. A decrease in systemic arterial pressure was observed in rabbits after $\alpha \mathrm{MSH}$ injection (3) and a fall in peripheral resistance was also observed after treatment with parathormone in adult dogs (2).

$\alpha \mathrm{MSH}$ increases blood flow to the heart, lungs, and adrenals in the newborn sheep. The increase in blood flow to the heart may be a result of coronary vasodilation due to an increase in cardiac work or a direct effect $\alpha \mathrm{MSH}$ on coronary circulation. It has been reported that coronary circulation increases after the administration in adult dogs of parathormone (2). The apparent increase in pulmonary blood flow observed after a $\alpha \mathrm{MSH}$ injection suggests an increase in peripheral arteriovenous shunting with subsequent trapping of recirculated microspheres by the capillaries in the lung, because an increase in bronchial circulation cannot account for the $198 \%$ increase of the blood flow to the lungs observed. Furthermore, an increase in arteriovenous shunting is consistent with the decrease in mean arterial pressure after $\alpha \mathrm{MSH}$ injection observed in both fetal sheep and young lambs. A physiologic control of arteriovenous shunting may provide the fetus and newborn with a mechanism to save oxygen or vital organs under a stressful condition. The increase in adrenal blood flow after $\alpha \mathrm{MSH}$ injection probably plays a role in the increased glucocorticoid secretion induced by $\alpha \mathrm{MSH}$ during the perinatal period in the sheep $(6,14)$.

The cardiovascular effects produced by $\alpha \mathrm{MSH}$ are not mediated through glucocorticoid release because we did not observe any cardiovascular changes after injecting eight times the estimated production of cortisol per day in newborn sheep. This lack of effect of cortisol is in agreement with reports in adult animals (11).

The cardiovascular effects of $\alpha \mathrm{MSH}$ could be mediated by catecholamines. To test this hypothesis, we used propranolol to block the beta-adrenergic receptors, which are responsible for the increase in heart rate and cardiac output and the vasodilatation observed in some vascular beds after epinephrine administration. After injection of $\alpha \mathrm{MSH}$, there was an increase in heart rate and aortic blood flow in propranolol-treated newborn lambs, establishing that the $\alpha \mathrm{MSH}$ action on the heart was not mediated by stimulation of beta-adrenergic receptors. These results agree with previous findings of an increase in heart rate after the administration of $\alpha \mathrm{MSH}$ in heart-lung preparations in adult dogs, in which catecholamines had been depleted by treatment with reserpine (10). Furthermore, Aldinger et al. (1) observed that $\alpha \mathrm{MSH}$ increased the ventricular contractile force and heart rate of anesthetized dogs previously treated with propranolol. In contrast, the decrease in mean arterial pressure induced by $\alpha \mathrm{MSH}$ was blocked by propranolol, suggesting that beta-adrenergic receptors may be implicated in the vasodilatation induced by $\alpha \mathrm{MSH}$ in young lambs; however, aortic blood flow increased significantly without change in mean arterial pressure, suggesting that there was still a decrease in systemic vascular resistance when propranolol was administered before $\alpha \mathrm{MSH}$. It has been shown that $\alpha \mathrm{MSH}$ increases tyrosinase activity in the skin of 

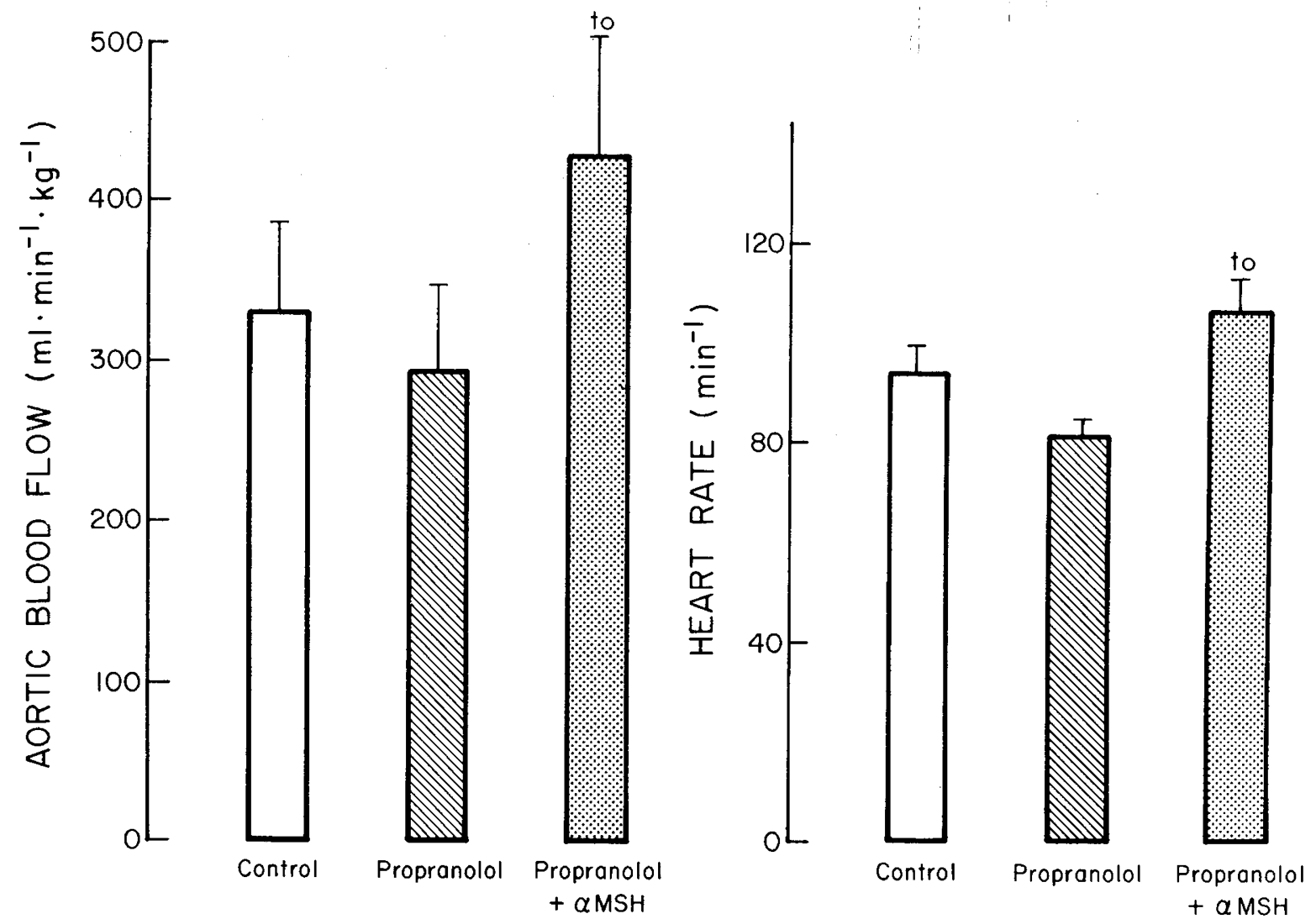

Fig. 4. Aortic blood flow and heart rate responses (mean \pm S.E.) of four young lambs (15-21-day-old) to an intravenous injection of $75 \mu \mathrm{g}$ of $\alpha$ MSH after beta-adrenergic blockade with propranolol (see text). ${ }^{+} P<0.005$ when compared to control and ${ }^{\circ} P<0.001$ when compared to propranolol alone.

adult mice (4). Tyrosinase catalyzes the conversion of tyrosine to DOPA, which is a precursor of dopamine, norepinephrine, and epinephrine.

$\alpha$ MSH could act directly on a myocardial adenylate cyclase different from that activated by catecholamines. This mechanism has been demonstrated for another polypeptide glucagon (12, 13), that also increases cardiac contractility (16), an effect not blocked by propranolol (5).

We do not know if the cardiovascular effects of $\alpha \mathrm{MSH}$ that we have described are of physiologic importance. Because the cardiovascular system of the fetal and young sheep can respond to $\alpha \mathrm{MSH}$, this hormone or a structurally related peptide could play a role in the regulation of the circulation in the perinatal period. We are not aware of measurements of $\alpha \mathrm{MSH}$ in plasma during the perinatal period in sheep. $\alpha \mathrm{MSH}$ has been shown to be present in high concentrations in the pituitaries of human (19) and of rhesus monkey fetuses (20) but was not found in fetal sheep pituitary (21). Even though $\alpha \mathrm{MSH}$ could be formed from peripheral degradation of precursor molecules, this finding does not rule out the possible existence of $\alpha \mathrm{MSH}$ in the circulation of the fetal and newborn sheep.

In lambs, the left ventricular output normally increases 200 $250 \%$ shortly after birth and then decreases $45 \%$ over the first 6 wk after birth; during the same period there is no significant changes in the response to beta-adrenergic blockade with propranolol (9). This finding suggests that factors other than catecholamines or beta-adrenergic tone are responsible for this dramatic initial increase of cardiac output and its subsequent decrease. The possibility that peptide hormones like $\alpha \mathrm{MSH}$ could be involved in the regulation of the circulation in the perinatal period deserves consideration.

\section{REFERENCES AND NOTES}

1. Aldinger, E. E., Hawley, W. D., Schally, A. V., and Kastin, A. S.: Cardiovascular actions of melanocyte stimulating hormone in the dog. J. Endocrinol., 56 613 (1973).

2. Crass, III, M. F. and Pang, P. K. T.: Parathyroid hormone: a coronary artery vasodilator. Science, 207: 1087 (1980).

3. Dyster-Aas, H K , and Krakau, C E $\Upsilon$. General effects of a $\alpha$ melanocyte stimulating hormone in the rabbit. Acta Endocrinol., 48: 609 (1965).

4. Gerschwind, I. I., Huseby, R. A., and Nishioka, R.: The effect of melanocytestimulating hormone on coat color in the mouse. Recent Prog. Horm. Res., 28: 91 (1972).

5. Glick, G. Parmley, W. W. Wechsler, A. S. and Sonnenblick, E. H - Glucagon: its enhancement of cardiac performance in the cat and dog and persistence of its inotropic action despite beta-receptor blockade with propranolol. Circ Res., 32: 789 (1968).

6. Glickman, J. A., Carson, D. G., and Challis, J. R. G.: Differential effects of synthetic adrenocorticotropin and $\alpha$ melanocyte-stimulating hormone on adrenal function in human and sheep fetuses. Endocrinology, 104: 34 (1979)

7. Heymann, M. A., Payne, B. D., Hoffman, J. I. E., and Rudolph, A. M.: Blood flow measurements with radionuclide-labeled particles. Prog. Cardiovasc. Dis., 20: 55 (1977).

8. Kastin, A. J., Kullander S., Borglin, N. E., Dahlberg, B., Dyster-Aas, K., Krakau, C. E. T., Ingvar, D. H., Miller, M. C., Bowers, C. Y., and Schally, A. U.: Extrapigmentary effects of melanocyte-stimulating hormone in amenorrheic women. Lancet, $I: 1007$ (1968).

9. Klopfenstein, H. S. and Rudolph, A. M.: Postnatal changes in the circulation and responses to volume loading in sheep. Circ. Res., 42: 839 (1978).

10. Krayer, O.. Astwood, E. B., Wand, D. R., and Alper, M. H.: Rate-increasing action of corticotropin and $\alpha$-intermedin in the isolated mammalian heart. Proc. Natl. Acad. Sci. USA, 47: 1227 (1961).

11. Lefer, A. M.: Corticosteroids and circulatory function. In: Greep, R. O. and Astwood. E. B., The Handbook of Physiology, Endocrinology. Vol VI, Adrenal Gland, pp. 191-207 (American Physiological Society, Washington, D.C. 1975).

12. Levey, G. S.: Restoration of glucagon responsiveness of solubilized myocardia adenyl cyclase by phosphatidylserine. Biochem. Biophys. Res. Commun. 43: 108 (1971).

13. Levey, G. S. and Epstein, S.E.: Activation of adenyl cyclase by glucagon in cat and human heart. Circ. Res., 24: 151 (1969).

14. Llanos, A. J., Ramachandran. J., Creasy, R. K., Rudolph, A. M., and SeronFerre, M.: $\alpha$-Melanocyte-stimulating hormone and adrenocorticotropin in the regulation of glucocorticoid secretion during the perinatal period in sheep. Endocrinology 105: 613 (1979).

15. Llanos, A. J., Green, J. R., Creasy, R. K., and Rudolph, A. M.: Increased heart rate response to parasympathetic and beta adrenergic blockade in growth retarded fetal lambs. Am. J. Obstet. Gynecol., 136: 808 (1980).

16. Lucchesi. B. R.: Cardiac actions of glucagon. Circ. Res., 22: 777 (1968).

17. Nathanielz, P. W.: Fetal Endocrinology: An Experimental Approach. pp. 162 (Amsterdam: North-Holland Publishing Company, 1976).

18. Rudolph, A. M. and Heymann, M. A. Cardiac output in the fetal lamb: The effects of spontaneous and induced changes of heart rate on right and left 
ventricular output. Am. J. Obstet. Gynecol., 124: 183 (1976).

19. Silman, R. E., Chard T., Lowry, P. J., Smith, I., and Young, I. M.: Human foetal pituitary peptides and parturition. Nature, 260:716 (1976).

20. Silman, R. E., Holland, D., Chard, T., Lowry, P. J., Hope, J., Robinson, J. S. and Thornburn, G. D.: The ACTH "family tree" of the rhesus monkey changes with development. Nature, 276: 526 (1978).

21. Silman, R. E., Holland, D., Chard, T., Lowry, P. J., Hope, J., Rees, L. H., Thomas, A., and Nathanielsz, P.: Adrenocorticotropin-related peptides in adult and foetal sheep pituitary glands. J. Endocrinol., 81: 19 (1979).

22. Winer, B. J.: Statistical principles in experimental design. pp. 261 (New York:McGraw-Hill Book Company, 1971).

23. Dr. Llanos is a recipient of a Postdoctoral Fellowship from the Bay Area Heart Research Association. His present address: Departmento de Ciencias Preclinicas, Division Oriente, Facultad de Medicina, Universidad de Chile, Casilla 16038, Santiago 9, Chile.
24. This work was partially presented at the 26th Annual Meeting of the Society for Gynecological Investigation, San Diego, USA, March 1979, and at the 17th Annual Meeting of the Latin American Society for Pediatric Research, Puerto Iguazu, Argentina, November, 1979.

25. We thank Dr. Barry Block for his assistance in writing the computer program utilized in the statistical analysis of the data. We thank Ms. Christine Roman and Mr. Carl McWatters for their skillful technical assistance and Ms. Mimi Zieger and Ms. Claudia Bello for their editorial assistance.

26. Requests for reprints should be addressed to: Dr. Michael A. Heymann, 1403 HSE, University of California, San Francisco, CA 94143.

27. This work was supported by grants from the U.S. Public Health Service: HD 06619, HL 06285, CA 16417.

28. Received for publication August 10, 1982

29. Accepted for publication March 24, 1983.

\title{
Regional Cerebral Blood Flow, Cerebral Blood Velocity, and Pulsatility Index in Newborn Dogs
}

\author{
DANIEL G. BATTON, ${ }^{(37)}$ JONATHAN HELLMANN, MILTON J. HERNANDEZ, AND \\ M. JEFFREY MAISELS \\ Division of Newborn Medicine, Department of Pediatrics, The Division of Neurology, Department of Medicine, \\ The Milton S. Hershey Medical Center of The Pennsylvania State University, College of Medicine, \\ Hershey, Pennsylvania, USA
}

\section{Summary}

A technique employing a Doppler ultrasound probe to measure cerebral blood velocity was used to study the cerebral circulation continuously in $\mathbf{3 0}$ newborn mongrel dogs. Utilizing a transfontanelle approach, the probe was maintained in fixed position throughout a given experiment. In 20 animals, changes in systolic, diastolic, and mean cerebral blood velocity during hypo- and hypercarbia were directly correlated $(P<0.01)$ with changes in regional cerebral blood flow ( $\mathrm{rCBF}$ ) determined in 12 regions of the brain by the $\left[{ }^{14} \mathrm{Cliodoantipyrine}\right.$ autoradiography technique. In an additional 10 dogs, multiple determinations of systolic, diastolic, and mean blood velocity were made over a wide range of $\mathrm{PaCO}_{2}$ values and found to be directly related to the $\mathrm{PaCO}_{2}(P$ $<0.001$ ). These data suggest that changes in cerebral blood velocity are closely related to changes in cerebral blood flow. We also calculated the pulsatility index (PI) from the peak systolic and end diastolic velocities and found a poor, but direct $(r=0.28$, $P<0.05$ ) relationship between the $\mathrm{PI}$ and $\mathrm{PaCO}_{2}$ rather than the indirect relationship, which has been suggested in published clinical studies. We conclude that the Doppler technique may be valuable in monitoring dynamic events of the neonatal cerebral circulation if a constant probe position is maintained. Our results suggest, however, that the PI is not a reliable index of cerebral vascular resistance.

\section{Abbreviations}

AUTC, area under the curve

CBF, cerebral blood flow

rCBF, regional cerebral blood flow

CVR, cerebral vascular resistance

PI, pulsatility index
Currently there is no acceptable noninvasive method of assessing instantaneous changes in $\mathrm{CBF}$ in human newborns. The experimental methods for determining CBF in animals using electromagnetic flowmeters (21), radioactive tracers (31), and microspheres (30) clearly are not adaptable to humans. The injection or inhalation of radioactive xenon has been used in human adults $(13,22)$ and newborns $(19,20)$, although its use in infants is limited because the technique is invasive and involves a radioactive substance. Occlusion plethysmography in newborn infants, although noninvasive, includes extracranial as well as intracranial blood flow $(4,5,17)$. With all of these methods only single or intermittent determinations can be made, and instantaneous changes in CBF cannot be determined.

Recently, transcutaneous Doppler ultrasound has been used to study the cerebral circulation in human adults $(8,28)$ and newborns (1) by determining changes in blood velocity. The advantages of this technique are that it is noninvasive and provides continuous information. Its limitations include the difficulty of standardizing the angle between the Doppler probe and the blood vessel, and defining the relationship between blood velocity and blood flow.

Bada et al. (1) were the first investigators to recognize the value of Doppler ultrasound in monitoring cerebral hemodynamics through the open anterior fontanelle in the human newborn. They attempted to minimize the Doppler's limitations by calculating the PI, rather than determining blood velocity directly. The PI is thought to be an index of CVR and, because it is a ratio, is less affected by probe position $(1,27)$. Despite several clinical studies utilizing the concept of PI in newborn infants $(6$, $11,12,15,18,23,24-26,29)$, the validity of this technique has not yet been confirmed.

In this study, we utilized newborn dogs to evaluate the transfontanelle Doppler method for determining cerebral blood ve- 